\title{
Is Intranasal Ketamine Safe and Effective as a Prehospital Analgesic?
}

Brett H. Shaw $\left(\mathbb{D}, \mathrm{MD}, \mathrm{MSc}^{*}\right.$; Marshall Ross, MD*

\section{INTRODUCTION}

\section{Background}

Primary care paramedics in British Columbia, Canada, have limited analgesic options other than nitrous oxide when transporting patients. Ketamine can be an effective analgesic when dosed appropriately.

\section{Objective}

The aim of this study was to compare the improvement in pain scores between intranasal ketamine and placebo when added to baseline inhaled nitrous oxide.

\section{METHODS}

\section{Design}

Single-centre randomized double blind control trial.

\section{Setting}

Out-of-hospital patients being cared for by primary care paramedics dispatched from a single station.

\section{Subjects}

Out-of-hospital patients with acute pain who reported a verbal numeric rating scale pain score $\geq 5$, and who wished to receive analgesia.

\section{Intervention}

$0.75 \mathrm{mg} / \mathrm{kg}$ intranasal ketamine v. placebo, both in addition to baseline nitrous oxide administration.

\section{Outcomes}

Primary outcome was the proportion of patients experiencing a reduction in verbal numeric rating scale score $\geq 2$ at 30 minutes.

\section{$\underline{\text { RESULTS }}$}

The key findings are displayed in Table 1.

\section{APPRAISAL}

\section{Strengths}

- True randomization

- Similarity between treatment and placebo groups

- Blinded and placebo controlled

- No patients were lost to follow-up after randomization

- Strong external validity and applicability

From: * Department of Emergency Medicine, University of Calgary, Calgary, AB, Canada.

Correspondence to: Dr. Brett Shaw, Department of Emergency Medicine, University of Calgary, C231 3280 Hospital Dr. NW, Calgary, AB T2N 4Z6, Canada; Email: brett.shaw@ucalgary.ca 


\begin{tabular}{|c|c|c|c|}
\hline Result & Ketamine & Placebo & $\begin{array}{l}\text { \% Difference } \\
(95 \% \mathrm{Cl})\end{array}$ \\
\hline $\begin{array}{l}\text { Primary outcome: proportion of patients experiencing } \geq 2 \text { point VNRS pain } \\
\text { score reduction at } 30 \mathrm{~min} \text { No. (\%) }\end{array}$ & $41(76)$ & $22(41)$ & $35(17-51)$ \\
\hline Secondary outcomes: median reduction in VNRS pain scores at 30 min (IQR) & $3(2$ to 5$)$ & 1 (0 to 4$)$ & \\
\hline Patient satisfaction median (IQR) & $5(2.8$ to 7$)$ & $2(0$ to 5$)$ & \\
\hline Major adverse events requiring intervention, no. (\%) & $0(0)$ & $0(0)$ & \\
\hline Minor adverse events not requiring intervention, no. (\%) [95\% Cl] & $37(62)$ [49-73] & $12(20)[12-32]$ & 42 (24?? 56$)$ \\
\hline
\end{tabular}

\section{Limitations}

- There was a component of unblinding with providers often able to identify treatment arms.

- There were no reported outcomes for patients beyond 30 minutes to better understand duration of treatment effect.

- Not all patients received nitrous oxide, limiting conclusions made about the combined effects of ketamine and nitrous oxide.

- This study was likely insufficiently powered to pick up rare adverse events.

\section{CONTEXT}

The role for ketamine as an analgesic in both the emergency department and prehospital setting is an evolving area with limited high quality evidence to guide practice. ${ }^{1}$ A systematic review examining the utility of sub-dissociative doses of intravenous ketamine found it to be a generally effective, opioid sparing analgesic option. ${ }^{1}$ Recent studies have compared the effects of intranasal ketamine with standard therapy for renal colic ${ }^{2}$ and primary headaches. ${ }^{3}$ Both studies did not find ketamine alone to be superior to standard therapy, but believed it provided a reasonable analgesic effect.

\section{BOTTOM LINE}

The PAIN-K study provides evidence that intranasal ketamine appears to be a potentially efficacious prehospital analgesic. Although this study was likely not powered to detect rare, serious adverse events, intranasal ketamine was quite well tolerated in the intervention group. In prehospital settings, it may be more difficult to obtain IV access; therefore, intranasal analgesic options are of increased importance. To the best of our knowledge, this is the first study to examine sub-dissociative dose intranasal ketamine for analgesia in a prehospital setting.

Keywords: Emergency medicine, anesthesia and analgesia, prehospital / EMS

\section{REFERENCES}

1. Ghate G, Clark E, Vaillancourt C. Systematic review of the use of low-dose ketamine for analgesia in the emergency department. Can 7 Emerg Med 2018;20(1):36-45.

2. Mozafari J, Maleki Verki M, Motamed H, Sabouhi A, Tirandaz F. Comparing intranasal ketamine with intravenous fentanyl in reducing pain in patients with renal colic: a doubleblind randomized clinical trial. Am 7 Emerg Med 2019; epub, doi: 10.1016/j.ajem.2019.05.049.

3. Benish T, Villalobos D, Love S, et al. The THINK (Treatment of Headache with Intranasal Ketamine) trial: a randomized controlled trial comparing intranasal ketamine with intravenous metoclopramide. 7 Emerg Med 2019;56(3):248-57.e1. 